\title{
A randomised phase $\|$ trial of preoperative chemotherapy of cisplatin-docetaxel or docetaxel alone for clinical stage IB/II non-small-cell lung cancer: results of a Japan Clinical Oncology Group trial (JCOG 0204)
}

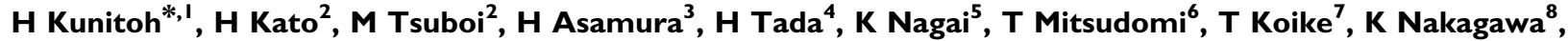 Y Ichinose', M Okada ${ }^{10}$, T Shibata" and N Saijo ${ }^{12}$, JCOG Lung Cancer Surgical Study Group, Tokyo, Japan}

'Department of Medical Oncology, National Cancer Center Hospital, 5-I I Tsukiji, Chuo-ku, Tokyo 104-0045, Japan; ${ }^{2}$ Department of Thoracic Surgery, Tokyo Medical University, 6-7-I Nishishinnjuku, Shinjuku-ku, Tokyo 160-0023, Japan; ${ }^{3}$ Division of Thoracic Surgery, National Cancer Center Hospital, 5-I-I Tsukiji, Chuo-ku, Tokyo 104-0045, Japan; ${ }^{4}$ Department of General Thoracic Surgery, Osaka City General Hospital, 2-I 3-22 Miyakojima-Hondori, Miyakojima-ku, Osaka 534-0021, Japan; ${ }^{5}$ Department of Thoracic Surgery, National Cancer Center Hospital East, 6-5-I Kashiwanoha, Kashiwashi, Chiba 277-8577, Japan; 'Department of Thoracic Surgery, Aichi Cancer Center, I-I Kanokoden, Chikusa-ku, Nagoya City, Aichi 464-868I, Japan; ${ }^{7}$ Department of Thoracic Surgery, Niigata Cancer Center, 2-15-3, Kawagishi-cho, Niigata-shi, Niigata 95 I-8566, Japan; ${ }^{8}$ Thoracic Oncology Center, Cancer Institute Hospital, 3- I0-6 Ariake, Koto-ku, Tokyo I 35-8550, Japan; ${ }^{9}$ Department of Thoracic Oncology, National Kyushu Cancer Center, 3-I-I Notame, Minami-ku, Fukuoka City, Fukuoka 81 I - I 395, Japan; ${ }^{10}$ Department of Surgical Oncology, Hiroshima University Research Institute for Radiation Biology and Medicine, 1-2-3 Kasumi, Minami-ku, Hiroshima City, Hiroshima 734-8553, Japan; "JCOG Data Center, Center for Cancer Control and Information Services, National Cancer Center, 5-I-I Tsukiji, Chuo-ku, Tokyo 104-0045, Japan; ${ }^{12}$ National Cancer Center Hospital East, 6-5-I

Kashiwanohara, Kashiwashi, Chiba 277-8577, Japan

Preoperative chemotherapy is a promising strategy in patients with early-stage resectable non-small-cell lung cancer (NSCLC); optimal chemotherapy remains unclear. Clinical (c-) stage IB/II NSCLC patients were randomised to receive either two cycles of docetaxel (D) - cisplatin (P) combination chemotherapy (D $60 \mathrm{mg} \mathrm{m}^{-2}$ and P $80 \mathrm{mg} \mathrm{m}^{-2}$ on day I) every 3-4 weeks or three cycles of $\mathrm{D}$ monotherapy $\left(70 \mathrm{mg} \mathrm{m}^{-2}\right)$ every 3 weeks. Thoracotomy was performed $4-5$ weeks (DP) or 3-4 weeks (D) after chemotherapy. The primary end point was I-year disease-free survival (DFS). From October 2002 to November 2003,80 patients were randomised. Chemotherapy toxicities were mainly haematologic and well tolerated. There were two early postoperative deaths with DP (one intraoperative bleeding and one empyema). Pathologic complete response was observed in two DP patients. Docetaxel-cisplatin was superior to D in terms of response rate (45 vs 15\%) and complete resection rate ( 95 vs $87 \%$ ). Both DFS and overall survival were better in DP. Disease-free survival at I, 2 and 4 years were 78, 65 and 57\% with DP, and were 62, 44 and 36\% with D, respectively. Preoperative DP was associated with encouraging resection rate and DFS data, and phase III trials for c-stage IB/II NSCLC are warranted.

British Journal of Cancer (2008) 99, 852-857. doi:I0.I038/sj.bjc.66046I3 www.bjcancer.com

Published online 26 August 2008

(C) 2008 Cancer Research UK

Keywords: cisplatin; docetaxel; lung cancer; non-small cell; preoperative chemotherapy; stage IB/II

Surgery is the standard of care for clinical (c-) stage IB/II non-small-cell lung cancer (NSCLC), but the treatment outcome remains poor, with 5 -year survival rates of $50 \%$ or less (Mountain, 1997; Goya et al, 2005). The majority of post-surgical relapse occurs as distant metastases (Pisters and Le Chevalier, 2005); therefore, effective systemic therapy is necessary. Recently, a series of postoperative adjuvant chemotherapy trials reported modest but significant improvement in survival, mainly in patients with pathological stage II or IIIA NSCLC (Arriagada et al, 2004; Scagliotti, 2005; Winton et al, 2005; Douillard et al,

*Correspondence: Dr H Kunitoh; E-mail: hkkunito@ncc.go.jp Received 28 April 2008; revised 4 July 2008; accepted 23 July 2008; published online 26 August 2008
2006). Compliance to the chemotherapy remains a problem (Arriagada et al, 2004; Scagliotti, 2005; Winton et al, 2005; Douillard et al, 2006).

On the other hand, previous small phase III trials had reported that preoperative chemotherapy was better than surgery alone in stage III NSCLC (Rosell et al, 1994; Roth et al, 1994). Recent trials of preoperative platinum-based chemotherapy have reported promising results in c-stage IB/II NSCLC (Pisters et al, 2000; Depierre et al, 2002; Rosell et al, 2002). One advantage of the preoperative chemotherapy is better tolerability and compliance.

No data are available, however, as to the optimal preoperative therapy strategy for early-stage NSCLC. Although platinum-based 'standard' combination chemotherapy regimens have widely been used and reported to be generally safe, results of randomised trials 
reported nonsignificant but modest excess of post-surgical morbidity and mortality (Depierre et al, 2002; Pisters et al, 2007). Monotherapy with an active agent is associated with lower response rate, but less toxicity (Delbaldo et al, 2004); it might well be favourable for preoperative therapy in early stage, when surgery must not be compromised by adjuvant therapy.

Docetaxel (D) is a semisynthetic taxoid derived from the European yew Taxus baccata. It is active against NSCLC either in monotherapy (D)(Fossella et al, 1994; Francis et al, 1994; Kunitoh et al, 1996) or in combination with cisplatin (DP) (Zalcberg et al, 1998; Fossella et al, 2003). In advanced NSCLC, DP was reported to be better than $\mathrm{P}$-vinca combination (Fossella et al, 2003; Kubota et al, 2004), one of the 'standard' adjuvant therapies. The DP combination was also reported to be active and promising as preoperative chemotherapy in c-stage III NSCLC (Betticher et al, 2006).

Docetaxel monotherapy, on the other hand, was reported to be not inferior to DP, with better tolerability in advanced NSCLC (Georgoulias et al, 2004). For stage III NSCLC, Mattson et al (2003) reported the results of $\mathrm{D}$ as preoperative chemotherapy; it was active, and did not compromise surgery.

On the basis of this rationale, we undertook a randomised phase II trial of DP $v s$ D in resectable, c-stage IB/II NSCLC. The objectives of the study were to evaluate the safety and efficacy of the preoperative chemotherapy and to select promising one for future phase III trials. The primary end point was the disease-free survival (DFS) rate at 1 year.

\section{PATIENTS AND METHODS}

\section{Patient eligibility criteria}

Patients with untreated, histologically or cytologically documented NSCLC with clinical stage IB (c-T2N0M0), IIA (c-T1N1M0) or IIB (c-T2N1M0 or T3N0M0) were eligible for study entry. Each patient was required to meet the following criteria: 20-74 years of age, Eastern Cooperative Oncology Group (ECOG) performance status (PS) of 0 or 1; measurable disease; and adequate organ function (leukocyte count $\geqslant 4000 / \mu \mathrm{l}$ and $\leqslant 12000 / \mu \mathrm{l}$, neutrophil count $\geqslant 2000 / \mu \mathrm{l}$, platelet count $\geqslant 10^{5} / \mu \mathrm{l}$, haemoglobin $\geqslant 10.0 \mathrm{~g} \mathrm{dl}^{-1}$, serum creatinine $\leqslant$ the upper limit of the institutional normal range (ULN), creatinine clearance calculated by the CockcroftGault formula $\geqslant 60 \mathrm{ml} \mathrm{min}^{-1}$, serum bilirubin $\leqslant \mathrm{ULN}$, serum ALT and AST $\leqslant 2 \times$ ULN and $\mathrm{PaO}_{2} \geqslant 70 \mathrm{~mm} \mathrm{Hg}$ ). Women who were pregnant or lactating were excluded from the study. Other exclusion criteria included patients with active infection, unstable angina or a history of myocardial infarction within 6 months, interstitial pneumonia or active lung fibrosis, uncontrolled diabetes or hypertension, systemic use of corticosteroid or active concomitant malignancy. Patients with tumour invading the first rib or more superior chest wall (Pancoast type) were also excluded. All mediastinal nodes measuring $1.0 \mathrm{~cm}$ or more in size on computed tomographic (CT) scans were required to be biopsied to be histologically benign before patient entry.

Patient eligibility was confirmed by the Japan Clinical Oncology Group Data Centre before registration. The study protocol was approved by the institutional review boards at each participating centre, and all patients provided written informed consent.

\section{Treatment plan}

This was an open-label, randomised trial. Patients were randomly assigned to one of two treatment arms. Dosages of the chemotherapy were based on the regulatory notes and clinical data in Japan (Kubota et al, 2004). In the DP combination arm, patients received $\mathrm{D}$ at $60 \mathrm{mg} \mathrm{m}^{-2}$ as a 1-h intravenous infusion followed by $\mathrm{P}$ at $80 \mathrm{mg} \mathrm{m}^{-2}$ as a 2-h infusion on day 1 . Two cycles of the chemotherapy were repeated at an interval of 4 weeks. The interval was permitted to be shortened to 3 weeks, if the patient was judged to have adequately recovered enough from the first cycle. Surgery (lobectomy or pneumonectomy with systematic lymph node dissection) was performed 4-5 weeks after completion or early termination of the chemotherapy. Patients in the D monotherapy arm received D at $70 \mathrm{mg} \mathrm{m}^{-2}$ as a 1 -h intravenous infusion on day 1 . Three cycles of the chemotherapy were repeated at 3 weeks intervals. Surgery in the D arm was performed 3-4 weeks after completion or early termination of chemotherapy. The preoperative periods were thus set at 8-10 weeks in each arm, which was designed to be easier to accept for the patients and the surgeons.

In each arm, when chemotherapy was judged to be ineffective with $\geqslant 10 \%$ unidirectional tumour growth, or when the patient experienced unacceptable toxicity (such as, grade 3 neurotoxicity, grade 2 pulmonary toxicity, grade 3 cardiac toxicity or other grade 4 non-haematological toxicities), chemotherapy was discontinued and the patient was taken up for surgery as clinically indicated. With minor toxicities, such as uncomplicated grade 4 haematologic or grade 3 non-critical, non-haematological toxicities, dosages of subsequent chemotherapy courses were reduced ( $\mathrm{P}$ by $20 \mathrm{mg} \mathrm{m}^{-2}$ and $\mathrm{D}$ by $10 \mathrm{mg} \mathrm{m}^{-2}$ ).

No protocol therapy was predetermined for those with unresectable tumours, either during chemotherapy or at operation, and those with microscopically or macroscopically incompletely resected tumours. Those who underwent curative resection were observed until recurrence without additional therapy.

Chemotherapy was supported with routine premedication for hypersensitivity and antiemetics. For the DP arm, ample hydration was ensured. Recombinant human granulocyte colonystimulating factor was administered when grade 4 neutropaenia or neutropaenic fever occurred.

\section{Patient evaluation and follow-up}

Before study enrolment, a complete medical history and physical examination, blood cell count determinations, biochemistry testing, chest X-ray, ECG, CT scan of the chest and CT scan or ultrasound of upper abdomen were conducted for each patient. Whole-brain CT or magnetic resonance imaging (MRI) or isotope bone scanning was performed if clinically indicated. Positron emission tomography (PET) was not widely available in Japan at the time of the protocol activation and was not routinely used for staging. Blood cell counts, differential WBC counts and biochemistry testing were performed weekly during each course of chemotherapy.

Toxicity of the chemotherapy was evaluated with the National Cancer Institute Common Toxicity Criteria Tumour (NCI-CTC; version 2.0). Tumour responses were assessed radiographically according to the RECIST guideline (Therasse et al, 2000). Response confirmation at 4 weeks or longer intervals was not necessitated. Response was assessed by the attending physicians in each participating institution, and no central confirmation was performed. Chest X-ray was taken at each course, and when suggested for even minor tumour growth $(\geqslant 10 \%)$, confirmatory chest CT was performed to decide on the continuation of chemotherapy.

After curative resection, the patients were followed up with periodic reevaluation. This included chest CT every 6 months for the first 2 years and annually thereafter, until 5 years or tumour recurrence.

\section{Statistical considerations}

This trial was designed as a randomised phase II selection design. Therefore, formal statistical hypothesis testing of the differences between the arms, including the calculation of $P$-values, was not to be performed. The aim was to select the 'preferable' preoperative chemotherapy arm for a future definitive phase III trial, with the DFS rate at 1 year as primary end point. The DFS was calculated 
from the date of enrolment by the Kaplan-Meier method, as was the overall survival (OS).The 'events' for the determination of the DFS included tumour relapse after curative surgery, death from any cause and non-curative operation. Those with non-curative operation include patients without surgery and those with incomplete resection, either microscopically or macroscopically. Non-curative operation was to be counted as an event on the date of registration, not on that of surgery. The sample size was determined to provide sufficient probability to choose the 'preferable' arm (Simon et al, 1985). Assuming DFS rates at 1 year of 70 and $80 \%, 40$ patients per arm were required to correctly select the arm that is not inferior with the probability of $84.9 \%$. The 'minimal' DFS rate of $70 \%$ was assumed with the prior report from North America, in which the 1- and 2-year survival rates were reported to be 85 and 56\%, respectively (Pisters et al, 2000). The assumption was rough and might well be inaccurate, for no DFS data were available from the literature. The randomisation was carried out by the JCOG data centre using a minimisation method with c-stage (IB vs II) and institutions as balancing factors.

The secondary end points included the objective tumour response to chemotherapy, complete resection rate, intra- and post-surgical morbidity/mortality and the OS rate. Tumour responses in both arms were compared using Fisher's exact test.

During the accrual period, an interim analysis was planned after 40 patients were randomised and followed up for at least 4 months. All analyses were performed with the SAS software version 9.1 (SAS Institute, Cary, NC, USA).

\section{RESULTS}

\section{Patient characteristics}

From October 2002 to October 2003, 80 patients from 18 institutions were enroled and randomised. After 40 patients were randomised, an interim analysis was carried out. Following the JCOG Data and Safety Monitoring Committee's review, the study was continued. One patient in the $\mathrm{D}$ arm was found to be ineligible because of the wrong histology (sarcoma). All 80 patients were analysed for characteristics and chemotherapy toxicity, and the 79 eligible patients were analysed for the clinical and pathological response to chemotherapy, surgical results, DFS and OS.

Table 1 lists the characteristics of the patients, which were well balanced between the arms.

\section{Chemotherapy delivery and toxicity}

Table 2 summarises the chemotherapy delivery, and Table 3 summarises toxicity in the subject group. Only $60 \%$ in the $\mathrm{D}$ arm completed the planned chemotherapy courses, mainly arising from the clinical ineffectiveness of the therapy. On the other hand, compliance was very good in the DP arm, and the toxicity was not greater. Hyponatraemia, probably due to hydration with $\mathrm{P}$ administration, was an unexpected toxicity in the DP arm, but it was clinically silent and transient in all the cases. All patients recovered without any particular management, with no clinically relevant sequelae. Other toxicities were mainly haematologic, and both chemotherapy arms were generally well tolerated by the patients.

\section{Clinical response and pathological results}

Table 4 shows the clinical responses to the chemotherapy. The overall response rates, $45 \%$ in the DP arm and $15 \%$ in the D arm, were compatible with earlier reports for each of the chemotherapy regimen in patients with NSCLC.

Thoracotomy was performed in 39 of the 40 patients in the DP arm, and in 37 of the 39 patients in the $\mathrm{D}$ arm. The tumour was surgically resected in $39(98 \%)$ patients in the DP arm, including
Table I Patient characteristics

\begin{tabular}{|c|c|c|}
\hline Arm & Cisplatin-docetaxel & Docetaxel alone \\
\hline$N$ & 40 & 40 \\
\hline \multicolumn{3}{|l|}{ Clinical stage } \\
\hline $\mathrm{IB}$ & 22 & 23 \\
\hline$\|$ & 18 & 17 \\
\hline \multicolumn{3}{|l|}{ Clinical T stage } \\
\hline $\mathrm{TI}$ & 5 & 5 \\
\hline $\mathrm{T} 2$ & 31 & 29 \\
\hline T3 & 4 & 6 \\
\hline \multicolumn{3}{|l|}{ Clinical N stage } \\
\hline No & 26 & 28 \\
\hline $\mathrm{NI}$ & 14 & 12 \\
\hline \multicolumn{3}{|l|}{ ECOG performance status } \\
\hline PSO & 35 & 31 \\
\hline PSI & 5 & 9 \\
\hline \multicolumn{3}{|l|}{ Histology } \\
\hline Adenocarcinoma & 30 & 24 \\
\hline Squamous cell carcinoma & 10 & 11 \\
\hline Others & 0 & 5 \\
\hline \multicolumn{3}{|c|}{ Body weight loss within 6 months } \\
\hline None & 24 & 22 \\
\hline$\leqslant 5 \mathrm{~kg}$ & 13 & 14 \\
\hline$>5 \mathrm{~kg}$ & । & 2 \\
\hline Missing & 2 & 2 \\
\hline \multicolumn{3}{|l|}{ Smoking } \\
\hline Median smoking & 40 pack-years & 40 pack-years \\
\hline Never-smoker & 6 & 8 \\
\hline
\end{tabular}

Table 2 Delivery of chemotherapy

\begin{tabular}{lcc}
\hline Arm & Cisplatin-docetaxel & Docetaxel alone \\
\hline$N$ & 40 & 40 \\
Completed & $38(95 \%)$ & $24(60 \%)$ \\
Not completed & 2 & 16 \\
Ineffective $^{\mathrm{a}}$ & $\mathrm{1}$ & 11 \\
Adverse event $^{\text {Patient refusal }}$ & 1 & 3 \\
Found ineligible & 0 & 1 \\
\hline
\end{tabular}

aneffectiveness was judged upon $\geqslant 10 \%$ unidirectional increase in tumour size, and did not necessarily mean progressive disease by RECIST.

pneumonectomy in 3 cases, bi-lobectomy in 2 cases and lobectomy in 34 cases. Tumour resection was performed in 35 (90\%) patients of the $\mathrm{D}$ arm, including pneumonectomy in 1 case, bi-lobectomy in 4 cases and lobectomy in 30 cases. Five patients, including four in the DP arm and one in the D arm, suffered from massive $(\geqslant 11)$ intraoperative bleeding: due to severe adhesion in three cases (two in DP and one in D arm), to incomplete suture of the autostapler resulting in injury of pulmonary artery in one case (DP arm) and accidental injury to the aorta in one case (DP arm). None was judged to be related to preoperative therapy. The postoperative complications included one patient with empyema and another with pulmonary oedema, both in the DP arm. There were two surgical deaths, both in the DP arm; one died on postoperative day 59 because of empyema, and another on postoperative day 2 because of massive intraoperative bleeding resulting from surgical injury to the aorta.

Pathological complete resection (R0), without residual tumour found either macroscopically or microscopically, was achieved in $38(95 \%)$ cases in the DP arm, and $34(87 \%)$ cases in the D arm. 
Table 3 Toxicity of chemotherapy

\begin{tabular}{|c|c|c|}
\hline Arm & Cisplatin-docetaxel & Docetaxel alone \\
\hline N & 40 & 40 \\
\hline Grade & $2 / 3 / 4(\%$ grade $3+4)$ & $2 / 3 / 4(\%$ grade $3+4)$ \\
\hline \multicolumn{3}{|l|}{ Haematological } \\
\hline Leukopaenia & |8/|4/| (38) & $12 / 15 / 2(43)$ \\
\hline Neutropaenia & $5 / 16 / 17(83)$ & $5 / 10 / 21(78)$ \\
\hline Anaemia & $4 / 0 / 0(0)$ & $7 / 0 / 0(0)$ \\
\hline Thrombocytopenia & $1 / 0 / 0(0)$ & $0 / 0 / 0(0)$ \\
\hline \multicolumn{3}{|l|}{ Nonhaematological } \\
\hline Total bilirubin & $4 / 0 / 0(0)$ & $0 / 0 / 0(0)$ \\
\hline Serum AST & 0/0/0 (0) & $3 / 1 / 0(3)$ \\
\hline Serum ALT & $5 / 0 / 0(0$ & $5 / 1 / 0(3)$ \\
\hline Serum creatinine & $3 / 0 / 0(0)$ & 0/0/0 (0) \\
\hline Hypoxia & 0/0/0 (0) & $3 / 0 / 0(0)$ \\
\hline Hypercalcaemia & 0/0/0 (0) & $0 / 1 / 0(3)$ \\
\hline Hyponatraemia & $-/ 6 / 0(15)$ & $-/ 1 / 0(3)$ \\
\hline Hypersensitivity & $0 / 0 / 0(0)$ & $0 / 1 / 0(3)$ \\
\hline Fatigue & $3 / 1 / 0(3)$ & $0 / 0 / 0(0)$ \\
\hline Constipation & $4 / 1 / 0(3)$ & $5 / 0 / 0(0)$ \\
\hline Diarrhea & $3 / 3 / 0(8)$ & $2 / 0 / 0(0)$ \\
\hline Nausea & $9 / 7 /-(18)$ & $0 / 0 /-(0)$ \\
\hline Vomiting & $5 / 1 / 0(3)$ & 0/0/0 (0) \\
\hline Febrile neutropaenia & $-/ 1 / 0(3)$ & $-/ 0 / 0(0)$ \\
\hline Infection with neutropaenia & $-/ 2 / 0(5)$ & $-/ 3 / 0(8)$ \\
\hline Infection without neutropaenia & $1 / 0 / 0(0)$ & $4 / 2 / 0(5)$ \\
\hline Neuropathy & 0/0/0 (0) & $\mathrm{I} / 0 / 0(0)$ \\
\hline Any grade $3 / 4$ toxicity & $35(88 \%)$ & $32(80 \%)$ \\
\hline \multicolumn{3}{|l|}{ Any grade $3 / 4$} \\
\hline Non-haematological toxicity & $15(38 \%)$ & $9(23 \%)$ \\
\hline
\end{tabular}

Table 4 Clinical response to chemotherapy based on RECIST

\begin{tabular}{lcc}
\hline Arm & Cisplatin-docetaxel & Docetaxel alone \\
\hline$N$ & 40 & 39 \\
Completed chemotherapy & $38(95 \%)$ & $24(62 \%)$ \\
CR & 1 & 0 \\
PR & 17 & 6 \\
CR+PR & 18 & 6 \\
SD & 18 & 23 \\
PD & 4 & 10 \\
NE & 0 & 0 \\
ORR & $45 \%$ & $15 \%$ \\
(95\% confidence interval) & $(29-62 \%)$ & $(6-31 \%)$ \\
\hline
\end{tabular}

$\mathrm{CR}=$ complete response; $\mathrm{NE}=$ not evaluable; $\mathrm{ORR}=$ overall response rate; $\mathrm{PD}=$ progressive disease; $\mathrm{PR}=$ partial response; $\mathrm{RECIST}=$ Response Evaluation Criteria in Solid Tumor; SD = stable disease.

On pathological examination, $23 \%$ of the 75 patients who underwent surgery were found to have N2 or N3 status. Pathologic CR was achieved in two patients, both in the DP arm. Clinical $\mathrm{N}$-stage was poorly correlated to pathological nodal status (Table 5).

\section{DFS and OS}

The DFS and OS were updated in November 2007. The DFS rates at 1, 2 and 4 years were 78,65 and $57 \%$ in the DP arm, and were 62,44 and $36 \%$ in the $\mathrm{D}$ arm, respectively (Figure 1). Table 6 summarises the outcome at 1 year, the primary end point of the study. The DFS rate at 1 year was $78 \%$ (31 out of 40 ) in the DP arm, which was consistent with the study assumption that it would be $80 \%$ in the 'better' arm, whereas it was a disappointing $62 \%$ ( 24 out of 39 ) in the D arm. The $16 \%$ difference was more than presumed in the protocol.
Table 5 Pathological results

\begin{tabular}{|c|c|c|c|c|c|c|}
\hline \multirow{2}{*}{$\begin{array}{l}\text { Arm } \\
\text { c-N stage }\end{array}$} & \multicolumn{3}{|c|}{ Cisplatin-docetaxel } & \multicolumn{3}{|c|}{ Docetaxel alone } \\
\hline & No & N I & Total & No & NI & Total \\
\hline Number of cases & 26 & 14 & 40 & 27 & 12 & 39 \\
\hline $\mathrm{p}-\mathrm{NO}$ & 17 & 6 & 23 & 18 & 4 & 22 \\
\hline $\mathrm{p}-\mathrm{NI}$ & 3 & 5 & 8 & 3 & I & 4 \\
\hline $\mathrm{p}-\mathrm{N} 2$ & 5 & 2 & 7 & 5 & 4 & 9 \\
\hline $\mathrm{p}-\mathrm{N} 3$ & 1 & 0 & I & 0 & 0 & 0 \\
\hline Not assessable & 0 & I & I & I & 3 & 4 \\
\hline
\end{tabular}

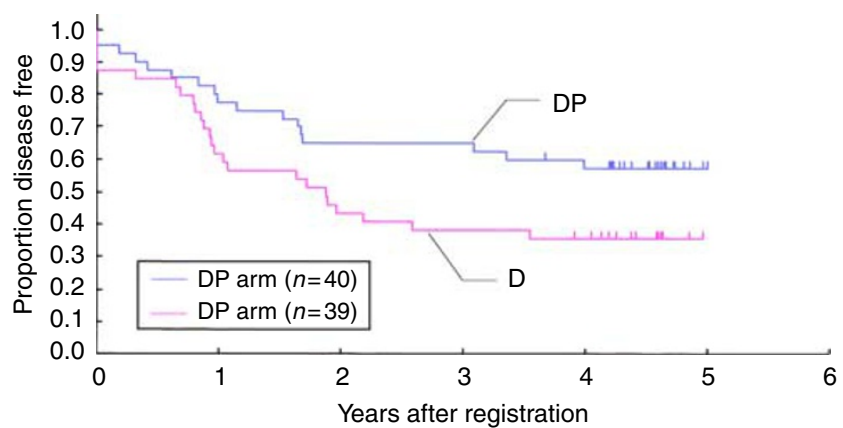

Figure I Disease-free survival.

Table 6 Outcome at I year

\begin{tabular}{lccc}
\hline Arm & Cisplatin-docetaxel & Docetaxel alone & Total \\
\hline Number of cases & 40 & 39 & 79 \\
Alive, disease-free & 31 & 24 & 55 \\
Alive with disease & 4 & 11 & 15 \\
Dead, due to cancer & 3 & 2 & 5 \\
Dead, treatment-related & 2 & 0 & 2 \\
Dead, other causes & 0 & 2 & 2 \\
\hline
\end{tabular}

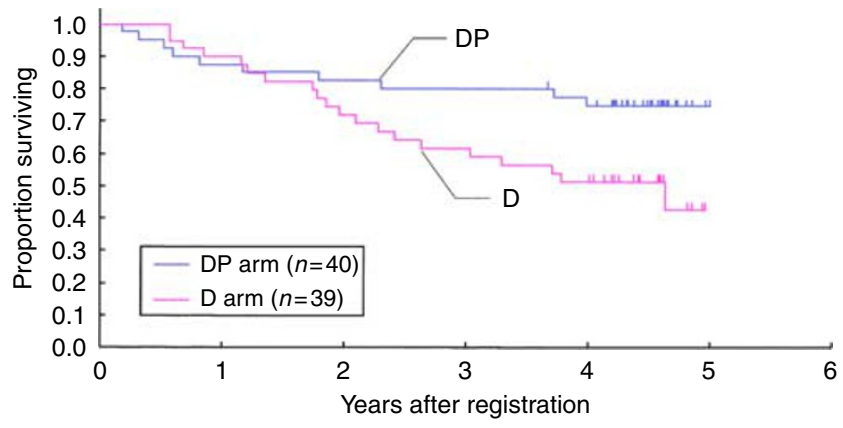

Figure 2 Overall survival.

The OS rates at 1,2 and 4 years were 88,83 and $75 \%$ in the DP arm, and were 87,72 and $57 \%$ in the D arm, respectively (Figure 2). Both the DFS and the OS rates were better in the DP arm. The OS was better in the DP arm in both adenocarcinoma and non-adenocarcinoma histological subtypes.

\section{DISCUSSION}

As compared with post-surgical adjuvant therapy, preoperative chemotherapy has several practical as well as theoretical advan- 
tages (Pisters et al, 2000; Pisters, 2003). The practical advantages include better patient tolerance and clinical visualisation of chemotherapy effect.

There are very few reports as to the optimal preoperative therapy strategy. The majority of trials have used 'standard' platinum-based doublets (Pisters, 2003). Although they are the 'standard' for advanced, stage IV NSCLC, a trade-off between the cytotoxic effect and toxicity of the chemotherapy, not only toxicity itself but also its influence on surgery and post-surgical morbidity and mortality (Depierre et al, 2002; Pisters et al, 2007), must be considered for preoperative therapy.

In this randomised phase II study, we evaluated DP combination chemotherapy and D monotherapy as preoperative treatment for early stage NSCLC. Although the DFS assumptions of the protocol, 70 vs $80 \%$ at 1 year, were rough and arbitrary due to lack of historical data, subsequent $S 9900$ trial (Pisters et al, 2007) showed DFS rate of $68 \%$ in the surgery alone group and $69 \%$ in those with preoperative carboplatin-paclitaxel therapy, consistent with our assumption.

Our results showed that single-agent $\mathrm{D}$ was inadequate in this setting; an unexpectedly high progression rate led to an early chemotherapy termination rate of as high as $40 \%$. The reason for the high PD rate is unknown. In addition, we tried to minimise the disadvantage of continuation of ineffective chemotherapy by defining the ineffectiveness as $\geqslant 10 \%$ tumour size increase instead of $\geqslant 20 \%$ in the RECIST guideline (Therasse et al, 2000). This subtle decision rule might require centralised confirmation. The DFS rate in the D arm was disappointing and was, in fact, very similar to that in the surgery-alone arm in the $\$ 9900$ study in the United States (Pisters et al, 2007).

On the other hand, both the DFS and OS rates of the DP arm were promising. Disease-free survival at 1 year of $78 \%$ was fully consistent with the estimation in the study protocol. Although our data do not refute other platinum-based chemotherapy as candidates of preoperative treatment, it would be justified to conclude that DP was active and promising, regardless of disappointing data of D monotherapy. One might argue that DFS at 1 year was too premature as an end point. Because the DFS and OS curves of the DP arm seem to have reached to plateau at 2 years, DFS at 2 years might be a more appropriate end point.

The number of chemotherapy courses of the DP combination was two, whereas many previous studies used three courses. In the North American trials with carboplatin and paclitaxel, three preoperative courses appeared to have no advantage when

\section{REFERENCES}

Arriagada R, Bergman B, Dunant A, Le Chevalier T, Pignon JP, Vansteenkiste J (2004) Cisplatin-based adjuvant chemotherapy in patients with completely resected non-small-cell lung cancer. $N$ Engl $J$ Med 350: 351-360

Betticher DC, Hsu Schmitz SF, Totsch M, Hansen E, Joss C, von Briel C, Schmid RA, Pless M, Habicht J, Roth AD, Spiliopoulos A, Stahel R, Weder W, Stupp R, Egli F, Furrer M, Honegger H, Wernli M, Cerny T, Ris HB (2006) Prognostic factors affecting long-term outcomes in patients with resected stage IIIA pN2 non-small-cell lung cancer: 5-year follow-up of a phase II study. Br J Cancer 94: 1099-1106

Cerfolio RJ, Ojha B, Bryant AS, Raghuveer V, Mountz JM, Bartolucci AA (2004) The accuracy of integrated PET-CT compared with dedicated PET alone for the staging of patients with nonsmall cell lung cancer. Ann Thorac Surg 78: 1017-1023; discussion 1017-1023

Delbaldo C, Michiels S, Syz N, Soria JC, Le Chevalier T, Pignon JP (2004) Benefits of adding a drug to a single-agent or a 2-agent chemotherapy regimen in advanced non-small-cell lung cancer: a meta-analysis. JAMA 292: $470-484$

Depierre A, Milleron B, Moro-Sibilot D, Chevret S, Quoix E, Lebeau B, Braun D, Breton JL, Lemarie E, Gouva S, Paillot N, Brechot JM, Janicot H, Lebas FX, Terrioux P, Clavier J, Foucher P, Monchatre M, Coetmeur D, compared with two courses (Pisters et al, 2000; Pisters, 2003). Although patients with 'two preoperative courses' were to have two additional courses after the operation, compliance to the postsurgical courses was very poor anyway (Pisters et al, 2000). But, as the majority of the patients appeared fit enough after two courses of DP and a major operation, we could consider the addition of a couple of postoperative chemotherapy cycles at least for responders.

One of the major disadvantages of preoperative therapy is the inaccuracy of the clinical staging, as reported by Depierre et al (2002). In our trial, $23 \%$ of the 74 patients who underwent thoracotomy were found to have $\mathrm{p}-\mathrm{N} 2 / \mathrm{N} 3$ disease. In Japan, mediastinoscopy for patients with mediastinal nodes measuring $1 \mathrm{~cm}$ or less in size on CT is not performed as a routine clinical practise, and nor was it in our study. Although the introduction of PET may improve the accuracy of the clinical staging, it would still be unlikely to be comparable to surgical staging (Lardinois et al, 2003; Cerfolio et al, 2004; Shim et al, 2005). This would inevitably lead to heterogeneity of the patient population, necessitating a sophisticated study design and large sample size for any future trial on preoperative therapy.

We conclude that the DP combination regimen is active and well tolerated as preoperative chemotherapy, with highly promising survival data. Future clinical trials are warranted based on our results.

\section{ACKNOWLEDGEMENTS}

We thank Ms Mieko Imai for the data management, and $\mathrm{Mr}$ Takashi Asakawa and Dr Naoki Ishizuka for the statistical analyses. This study was supported by the Grant-in-Aid for Cancer Research (114S-2, 14S-4, 17S-2, 17S-5) and Health Sciences Research Grant from the Ministry of Health, Labour and Welfare of Japan. Presented in part at the 40th Annual Meeting of the American Society of Clinical Oncology, 5-8 June 2004, New Orleans, LA, and at the 11th World Conference on Lung Cancer, 3-6 July 2005, Barcelona, Spain. Registered in http://www.clinical trials.gov. ClinicalTrials.gov number, NCT00132639.

\section{Conflict of interest}

Hideo Kunitoh, Masahiro Tsuboi, Yukito Ichinose and Nagahiro Saijo have received honoraria from Sanofi-Aventis.
Level MC, Leclerc P, Blanchon F, Rodier JM, Thiberville L, Villeneuve A, Westeel V, Chastang C (2002) Preoperative chemotherapy followed by surgery compared with primary surgery in resectable stage I (except T1N0), II, and IIIa non-small-cell lung cancer. J Clin Oncol 20: 247-253 Douillard JY, Rosell R, De Lena M, Carpagnano F, Ramlau R, Gonzales-Larriba JL, Grodzki T, Pereira JR, Le Groumellec A, Lorusso V, Clary C, Torres AJ, Dahabreh J, Souquet PJ, Astudillo J, Fournel P, Artal-Cortes A, Jassem J, Koubkova L, His P, Riggi M, Hurteloup P (2006) Adjuvant vinorelbine plus cisplatin vs observation in patients with completely resected stage IB-IIIA non-small-cell lung cancer (Adjuvant Navelbine International Trialist Association [ANITA]): a randomised controlled trial. Lancet Oncol 7: 719-727

Fossella F, Pereira JR, von Pawel J, Pluzanska A, Gorbounova V, Kaukel E, Mattson KV, Ramlau R, Szczesna A, Fidias P, Millward M, Belani CP (2003) Randomized, multinational, phase III study of docetaxel plus platinum combinations vs vinorelbine plus cisplatin for advanced non-small-cell lung cancer: the TAX 326 study group. J Clin Oncol 21: 3016-3024

Fossella FV, Lee JS, Murphy WK, Lippman SM, Calayag M, Pang A, Chasen M, Shin DM, Glisson B, Benner S et al. (1994) Phase II study of docetaxel for recurrent or metastatic non-small-cell lung cancer. J Clin Oncol 12: $1238-1244$ 
Francis PA, Rigas JR, Kris MG, Pisters KM, Orazem JP, Woolley KJ, Heelan RT (1994) Phase II trial of docetaxel in patients with stage III and IV non-small-cell lung cancer. J Clin Oncol 12: $1232-1237$

Georgoulias V, Ardavanis A, Agelidou A, Agelidou M, Chandrinos V, Tsaroucha E, Toumbis M, Kouroussis C, Syrigos K, Polyzos A, Samaras N, Papakotoulas P, Christofilakis C, Ziras N, Alegakis A (2004) Docetaxel vs docetaxel plus cisplatin as front-line treatment of patients with advanced non-small-cell lung cancer: a randomized, multicenter phase III trial. J Clin Oncol 22: 2602-2609

Goya T, Asamura H, Yoshimura H, Kato H, Shimokata K, Tsuchiya R, Sohara Y, Miya T, Miyaoka E (2005) Prognosis of 6644 resected nonsmall cell lung cancers in Japan: a Japanese lung cancer registry study. Lung Cancer 50: $227-234$

Kubota K, Watanabe K, Kunitoh H, Noda K, Ichinose Y, Katakami N, Sugiura T, Kawahara M, Yokoyama A, Yokota S, Yoneda S, Matsui K, Kudo S, Shibuya M, Isobe T, Segawa Y, Nishiwaki Y, Ohashi Y, Niitani H (2004) Phase III randomized trial of docetaxel plus cisplatin vs vindesine plus cisplatin in patients with stage IV non-small-cell lung cancer: the Japanese Taxotere Lung Cancer Study Group. J Clin Oncol 22: 254-261

Kunitoh H, Watanabe K, Onoshi T, Furuse K, Niitani H, Taguchi T (1996) Phase II trial of docetaxel in previously untreated advanced non-smallcell lung cancer: a Japanese cooperative study. J Clin Oncol 14: $1649-1655$

Lardinois D, Weder W, Hany TF, Kamel EM, Korom S, Seifert B, von Schulthess GK, Steinert HC (2003) Staging of non-small-cell lung cancer with integrated positron-emission tomography and computed tomography. $N$ Engl J Med 348: 2500-2507

Mattson KV, Abratt RP, ten Velde G, Krofta K (2003) Docetaxel as neoadjuvant therapy for radically treatable stage III non-small-cell lung cancer: a multinational randomised phase III study. Ann Oncol 14: $116-122$

Mountain CF (1997) Revisions in the International System for Staging Lung Cancer. Chest 111: $1710-1717$

Pisters KM (2003) Induction chemotherapy in early-stage non-small-cell lung cancer. Curr Oncol Rep 5: 307-308

Pisters K, Vallieres E, Bunn Jr PA, Crowley J, Chansky K, Ginsberg R, Gandara DR (2007) S9900: surgery alone or surgery plus induction paclitaxel/carboplatin chemotherapy in early stage non-small cell lung cancer: follow-up on a phase III trial. I Clin Oncol 25: 389S (abstract)

Pisters KM, Ginsberg RJ, Giroux DJ, Putnam Jr JB, Kris MG, Johnson DH, Roberts JR, Mault J, Crowley JJ, Bunn Jr PA (2000) Induction

\section{Appendix}

The following institutions and investigators participated in the trial:

Tohoku University Hospital (Takashi Kondo and Akira Sakurada), Tochigi Cancer Center (Haruhisa Matsuguma), Saitama Cancer Center (Hirohiko Akiyama), National Cancer Center Hospital East (Kanji Nagai, Junji Yoshida and Nagahiro Saijo), National Cancer Center Hospital (Hisao Asamura, Kenji Suzuki and Hideo Kunitoh), Kyorin University School of Medicine (Tomoyuki Goya and Yoshihiko Koshiishi), Tokyo Medical University (Harubumi Kato and Masahiro Tsuboi), Cancer Institute Hospital (Ken Nakagawa and Yukitoshi Satoh), Yokohama Munipical Citizen's Hospital (Koshiro Watanabe and chemotherapy before surgery for early-stage lung cancer: a novel approach. Bimodality Lung Oncology Team. J Thorac Cardiovasc Surg 119: $429-439$

Pisters KM, Le Chevalier T (2005) Adjuvant chemotherapy in completely resected non-small-cell lung cancer. J Clin Oncol 23: 3270 - 3278

Rosell R, Gomez-Codina J, Camps C, Maestre J, Padille J, Canto A, Mate JL, Li S, Roig J, Olazabal A, Canela M, Ariza A, Skacel Z, Morera-Prat J, Abad A (1994) A randomized trial comparing preoperative chemotherapy plus surgery with surgery alone in patients with non-small-cell lung cancer. $N$ Engl J Med 330: $153-158$

Rosell R, Lord RV, Taron M, Reguart N (2002) DNA repair and cisplatin resistance in non-small-cell lung cancer. Lung Cancer 38: 217-227

Roth JA, Fossella F, Komaki R, Ryan MB, Putnam Jr JB, Lee JS, Dhingra H, De Caro L, Chasen M, McGavran M, Atkinson EN, Hong WK (1994) A randomized trial comparing perioperative chemotherapy and surgery with surgery alone in resectable stage IIIA non-small-cell lung cancer. J Natl Cancer Inst 86: 673-680

Scagliotti GV (2005) The ALPI Trial: the Italian/European experience with adjuvant chemotherapy in resectable non-small lung cancer. Clin Cancer Res 11: 5011s-5016s

Shim SS, Lee KS, Kim BT, Chung MJ, Lee EJ, Han J, Choi JY, Kwon OJ, Shim YM, Kim S (2005) Non-small cell lung cancer: prospective comparison of integrated FDG PET/CT and CT alone for preoperative staging. Radiology 236: 1011-1019

Simon R, Wittes RE, Ellenberg SS (1985) Randomized phase II clinical trials. Cancer Treat Rep 69: 1375-1381

Therasse P, Arbuck SG, Eisenhauer EA, Wanders J, Kaplan RS, Rubinstein L, Verweij J, Van Glabbeke M, van Oosterom AT, Christian MC, Gwyther SG (2000) New guidelines to evaluate the response to treatment in solid tumors. European Organization for Research and Treatment of Cancer, National Cancer Institute of the United States, National Cancer Institute of Canada. J Natl Cancer Inst 92: 205-216

Winton T, Livingston R, Johnson D, Rigas J, Johnston M, Butts C, Cormier Y, Goss G, Inculet R, Vallieres E, Fry W, Bethune D, Ayoub J, Ding K, Seymour L, Graham B, Tsao MS, Gandara D, Kesler K, Demmy T, Shepherd F (2005) Vinorelbine plus cisplatin vs observation in resected non-small-cell lung cancer. $N$ Engl J Med 352: 2589-2597

Zalcberg J, Millward M, Bishop J, McKeage M, Zimet A, Toner G, Friedlander M, Barter C, Rischin D, Loret C, James R, Bougan N, Berille J (1998) Phase II study of docetaxel and cisplatin in advanced non-smallcell lung cancer. J Clin Oncol 16: 1948-1953

Jun-ichi Nitadori), Niigata Cancer Center Hospital (Teruaki Koike and Yasushi Yamato), Aichi Cancer Center Hospital (Tetsuya Mitsudomi and Shoichi Mori), Osaka Prefectural Hospital Organization Osaka Medical Center for Cancer and Cardiovascular Diseases (Ken Kodama and Masahiko Higashiyama), Osaka Prefectural Hospital Organization Osaka Prefectural Medical Center for Respiratory and Allergic Disease (Mitsunori Ota), Osaka City General Hospital (Hirohito Tada and Ryoji Yamamoto), Hyogo Cancer Center (Morihito Okada, Masahiro Yoshimura and Koichiro Iwanaga), National Hospital Organization Shikoku Cancer Center (Motohiro Yamashita), National Kyushu Cancer Center (Yukito Ichinose and Koji Yamazaki), Nagasaki University School of Medicine (Takeshi Nagayasu and Tsutomu Tagawa). 